\title{
MODELLING REVERSIBLE INHIBITION OF IRREVERSIBLE ELECTRO-OXIDATION
}

\section{MILIVOJ LOVRIĆ * AND ŠEBOJKA KOMORSKY-LOVRIĆ}

\author{
Divkovićeva 13, HR 10090 Zagreb, Croatia.
}

\begin{abstract}
Totally irreversible electro-oxidation of dissolved reactant that is inhibited by the formation of oxide on the electrode surface is analysed theoretically. In the reverse, cathodic branch of staircase cyclic voltammogram these two parallel reactions exhibit both cathodic minimum and anodic maximum. The potentials of these extremes depend on the kinetics of oxide formation.
\end{abstract}

Keywords: Voltammetry, Inhibition, Oxide, Simulation.

\section{INTRODUCTION}

Electro-oxidation of methanol is investigated as a part of the development of fuel cells $[1-11]$. On platinum electrode this reaction is hindered by the formation of surface oxide [1,7], or by the adsorption of carbon monoxide [2, 11]. In the reverse branch of cyclic voltammogram the oxide layer is reduced to metallic platinum and the anodic peak corresponding to methanol oxidation appears again. Similar anomalous cyclic voltammograms that consist of anodic peaks in both anodic and cathodic branches were observed in electro-oxidations of ethanol [12 - 16], glycerol [16, 17] and formic acid [18]. Apart from pure platinum $[1,6-8,11,14,16,18]$ and its alloys with ruthenium $[2,3]$ and rhodium [13], various catalysts were used, such as palladium [5, 10, 12], gold [17], $\mathrm{Fe}_{2}\left(\mathrm{MoO}_{4}\right)_{3}$ [4] and nickel [15]. On majority of electrodes the oxidation of methanol is faster after the reactivation than before the deactivation of catalyst. In this paper the theoretical model of irreversible electrode reaction of dissolved reactant that runs parallel with the reversible formation of metal oxide on the surface of the working electrode is developed. It is assumed that the oxide prevents the heterogeneous electron transfer. The purpose of the work is to investigate the relationship between cyclic voltammogram of the volume reaction and the stability of surface oxide.

\section{MODELS}

In the first model the oxidation of metal electrode surface is considered:

$$
\mathrm{M}+\mathrm{H}_{2} \mathrm{O} \leftrightarrow \mathrm{MO}+2 \mathrm{H}^{+}+2 \mathrm{e}^{-}
$$

This reaction is described by the following differential equations:

$$
\begin{aligned}
& d \Gamma_{M O} / d t=-k_{s 1} \exp \left(-\alpha_{1} \varphi\right)\left[\Gamma_{M O}-\exp (\varphi)\left(\Gamma_{\max }-\Gamma_{M O}\right)\right] \\
& d \Gamma_{M O} / d t=I_{\text {surf }} / 2 F S_{\text {tot }} \\
& \varphi=2 F\left(E-E_{2}^{0}\right) / R T \\
& t=0: \quad \Gamma_{M O}=0
\end{aligned}
$$

The definitions of all symbols are given in Table 1. Differential equations (2) and (3) are solved numerically [19]. In the staircase cyclic voltammetry the scan rate is defined as $v=\Delta E / \tau$, where $\Delta E$ is the potential increment and $\tau$ is the step duration. In the simulation the time increment was defined as $d=\tau / 50$. The current is sampled at the end of each step. The solution is a system of recursive formulae for the dimensionless current density and the surface coverage:

$$
\begin{aligned}
& \Phi_{\text {surf }, m}=\kappa \exp \left(-\alpha_{1} \varphi_{m}\right)\left[\exp \left(\varphi_{m}\right)-\left(1+\exp \left(\varphi_{m}\right)\right) f \sum_{j=1}^{m-1} \Phi_{\text {surf }, j}\right][1+ \\
& \left.\kappa f \exp \left(-\alpha_{1} \varphi_{m}\right)\left(1+\exp \left(\varphi_{m}\right)\right)\right]^{-1} \\
& \theta_{M O, m}=f \sum_{j=1}^{m} \Phi_{\text {surf }, j} \\
& \Phi_{\text {surf }}=I_{\text {surf }} R T / 2 F S_{\text {tot }} \Gamma_{\text {max }} F v \\
& \theta_{M O}=\Gamma_{M O} / \Gamma_{\max } \\
& \kappa=k_{s 1} R T / F v \\
& f=F \Delta E / 50 R T \\
& m=1,2,3 \ldots \\
& 4661
\end{aligned}
$$

Table 1

\section{Meanings of symbols}

$\alpha_{1}, \alpha_{2} \quad$ Transfer coefficients of reactions (1) and (13)

$c_{A} \quad$ Concentration of species A

$c_{A}^{*} \quad$ Concentration of species A in the bulk of solution

$D \quad$ Diffusion coefficient

d Time increment

E Electrode potential

$E_{1}^{0} \quad$ Standard potential of the electrode reaction (13)

$E_{2}^{0} \quad$ Standard potential of the electrode reaction (1)

$\Delta E \quad$ Potential step in staircase cyclic voltammetry

$F \quad$ Faraday constant

$\Gamma_{M O} \quad$ Surface concentration of metal oxide

$\Gamma_{\max } \quad$ Maximum surface concentration of metal oxide

$I_{\text {surf }}, I_{\text {vol }}$ Currents of electrode reactions (1) and (13)

$k_{s 1}, k_{s 2} \quad$ Rate constants of electrode reactions (1) and (13)

$R \quad$ Gass constant

$S \quad$ Active area of electrode surface

$S_{\text {tot }} \quad$ Total area of electrode surface

$T \quad$ Temperature

$t \quad$ Time

$\theta \quad$ Surface coverage

$v \quad$ Scan rate

The second model describes totally irreversible electro-oxidation of dissolved reactant giving dissolved product:

$$
\mathrm{A} \rightarrow \mathrm{B}^{+}+\mathrm{e}^{-}
$$

For the stationary, planar diffusion the following differential equation must be solved:

$$
\begin{aligned}
& \partial c_{A} / \partial t=D \partial^{2} c_{A} / \partial x^{2} \\
& t=0, x \geq 0: \quad c_{A}=c_{A}^{*} \\
& t>0, x \rightarrow \infty: \quad c_{A} \rightarrow c_{A}^{*} \\
& x=0: \quad D\left(\partial c_{A} / \partial x\right)_{x=0}=I_{v o l} / F S \\
& I_{v o l} / F S=k_{S 2} \exp \left[\left(1-\alpha_{2}\right)(F / R T)\left(E-E_{1}^{0}\right)\right] c_{A, x=0}
\end{aligned}
$$

The solution was obtained by the digital simulation method [20]. Dimensionless current $\Phi_{v o l}=I_{v o l} \sqrt{R T} / F S c_{A}^{*} \sqrt{D F v}$ was calculated for the staircase cyclic voltammetry. Kinetics of reaction (13) depends on the dimensionless rate constant $\lambda=k_{s 2} \sqrt{R T / D v F}$. It is assumed that the surface oxide calculated in the first model inactivates the electrode surface for the reaction (13). On active parts of electrode the current flows whereas on inactive parts the flux is zero. The consequence is the accumulation of reactant at the blocked surface. After the electrode reactivation the concentration gradient of the reactant at the electrode surface is higher than the gradient at the same potential in the absence of electrode deactivation. For this reason the second anodic peak current is higher than the current at the second peak potential in the absence of deactivation [21]. 
The currents of the surface reaction (1) and volume reaction (13) are connected by the following relationship:

$\Phi_{\text {vol }}=\Phi_{\text {surf }} / Z$

$Z=c_{A}^{*} \sqrt{D R T / F v} / 2 \Gamma_{\max }$

If $c_{A}^{*}=0.01 \mathrm{~mol} / \mathrm{L}, \Gamma_{\max }=1.5 \times 10^{-9} \mathrm{~mol} / \mathrm{cm}^{2}, D=9 \times 10^{-6} \mathrm{~cm}^{2} / \mathrm{s}$ and $v=0.1$ $\mathrm{V} / \mathrm{s}$, the factor of proportionality is $Z=5$.

\section{RESULTS AND DISCUSSION}

Fig. 1A shows dimensionless current of electrode reaction (1) in staircase cyclic voltammetry. The formation of surface oxide and its reduction are shown in Fig. 1B. The current exhibits anodic maximum at $0.140 \mathrm{~V}$ and cathodic minimum at $-0.040 \mathrm{~V} v s . E_{1}^{0}$. In the anodic branch of cyclic voltammogram the electrode surface is partially covered by the oxide in the potential range between $0.025 \mathrm{~V}$ and $0.180 \mathrm{~V} v s . E_{1}^{0}$ and totally covered at higher potentials. In the reverse, cathodic branch the oxide cover gradually disappears between $0.080 \mathrm{~V}$ and $-0.080 \mathrm{~V} v s$. $E_{1}^{0}$. So, the electrode reaction (13) is completely inhibited between $0.180 \mathrm{~V}$ and $0.300 \mathrm{~V} v s$. $E_{1}^{0}$ during the forward scan and between 0.300 $\mathrm{V}$ and $0.080 \mathrm{~V} v s . E_{1}^{0}$ during the backward scan.

(A)

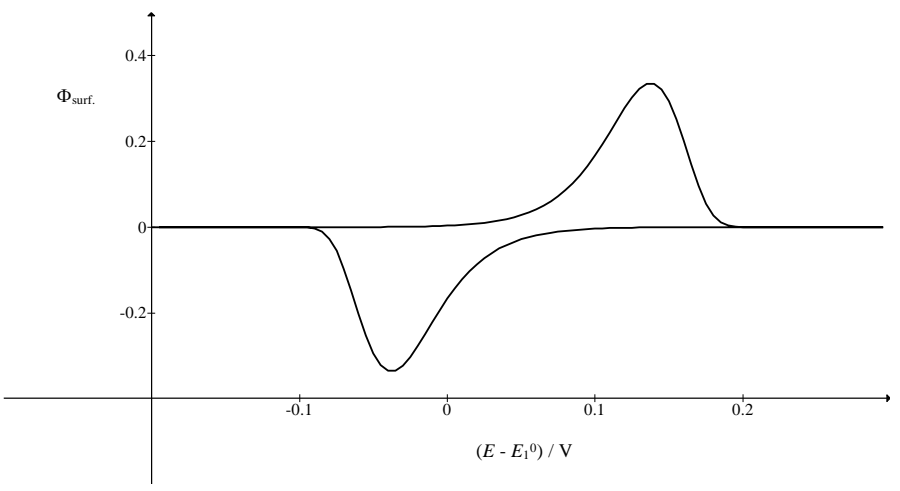

(B)

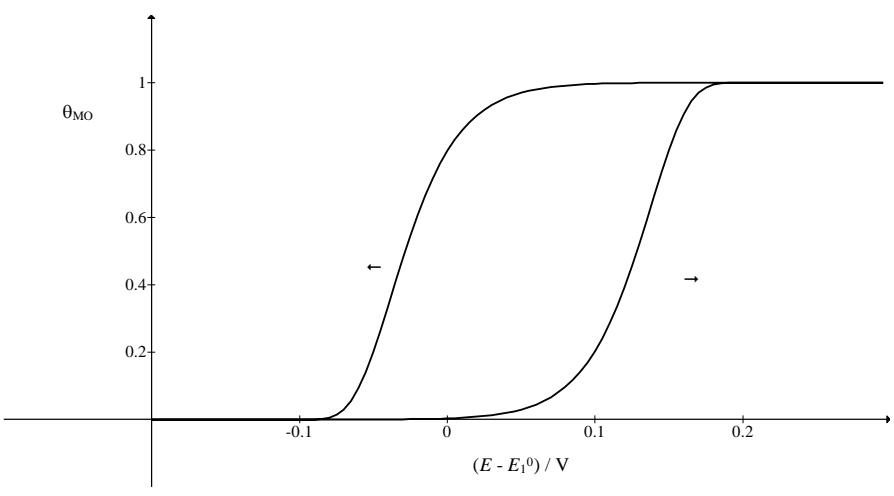

Fig. 1 Dimensionless current (A) and surface coverage (B) of electrode reaction (1). $E_{2}^{0}-E_{1}^{0}=0.050 \mathrm{~V}, \kappa=0.03, \alpha_{1}=0.5$ and $\Delta E=5 \mathrm{mV}$.

An example of possible influence of reversible inhibition on the response of reaction (13) is shown in Fig. 2. The curve 1 is characterised by the maximum at $0.095 \mathrm{~V}$ in the anodic branch and the minimum at $0.005 \mathrm{~V}$ and the second maximum at $-0.070 \mathrm{~V}$ vs. $E_{1}^{0}$ in the reverse branch of cyclic voltammogram. The minimum is caused by the reduction of oxide and the second maximum is caused by the oxidation of reactant $\mathrm{A}$ on the reactivated electrode surface. The curve 1 was calculated under assumption that the dimensionless rate constant of the reaction (13) on the electrode surface before the inactivation $\left(\lambda_{1}\right)$ is ten times smaller than the rate constant after the reactivation $\left(\lambda_{2}\right)$. If these rate constants are equal, the second maximum is smaller than the current at the second peak potential in the anodic branch, as can be seen in Fig. 3. This is because the hydrodynamic conditions at the inactive surface are not identical to the initial conditions.

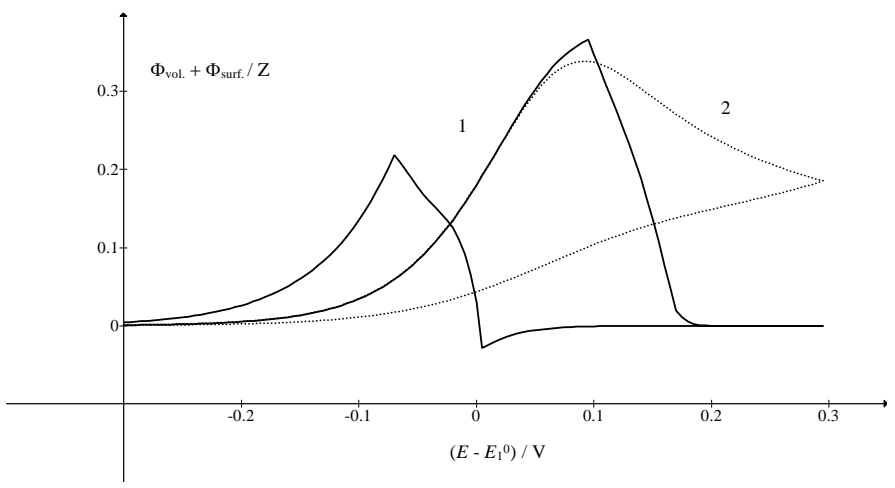

Fig. 2 Staircase cyclic voltammetry of electrode reaction (13) that is inhibited by surface oxide. The sum of dimensionless currents of volume and surface reactions (1) and the current of reaction (13) in the absence of oxide (2). $E_{2}^{0}-E_{1}^{0}$ $=0.050 \mathrm{~V}, \kappa=0.03, \alpha_{1}=0.5, \lambda_{1}=0.25, \lambda_{2}=2.5, \alpha_{2}=0.5, \Delta E=5 \mathrm{mV}$ and $Z=$ 5 .

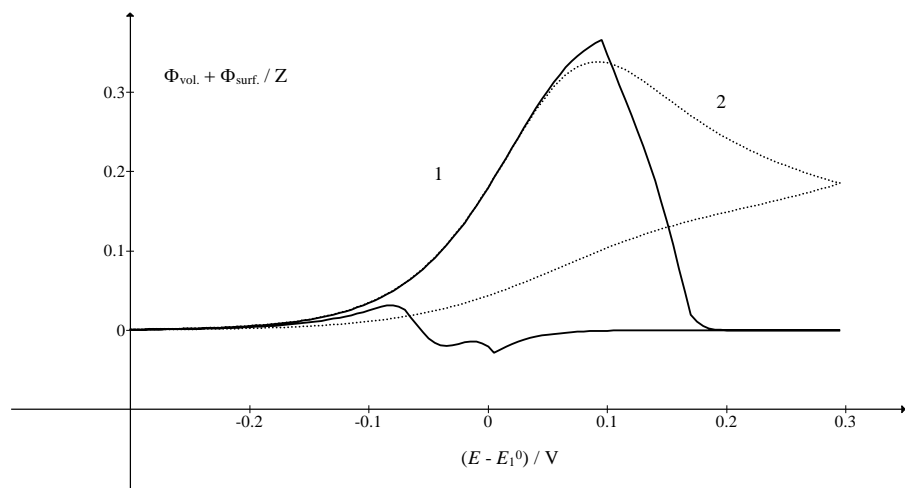

Fig. 3 The sum of dimensionless currents of electrode reactions (1) and (13); $\lambda_{2}=0.25$ and all other data are as in Fig. 2 .

The influence of the difference between standard potentials of electrode reactions (1) and (13) on the response of reaction (13) is shown in Fig. 4. If $E_{2}^{0}=$ $E_{1}^{0}$, the first and the second maxima appear at $0.045 \mathrm{~V}$ and $-0.120 \mathrm{~V}$ vs. $E_{1}^{0}$, respectively. The difference between these two potentials is $165 \mathrm{mV}$, which is equal to the difference between anodic peak potentials that are shown in Fig. 2. However, the medians of anodic peak potentials in Figs. 4 and 2 are $-0.0375 \mathrm{~V}$ and $0.0125 \mathrm{~V}$ vs. $E_{1}^{0}$, respectively. As the consequence of lower median, the anodic peak currents are smaller in Fig. 4 than in Fig. 2.

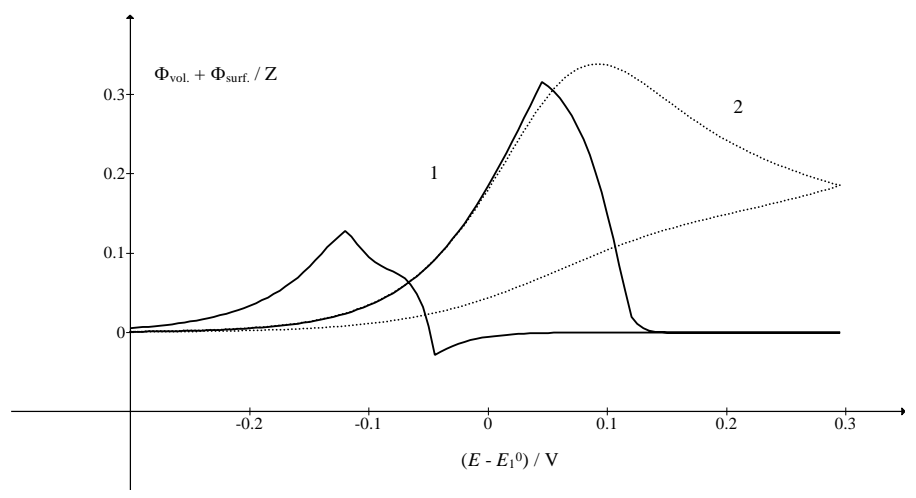

Fig. 4 The sum of dimensionless currents of electrode reactions (1) and (13); $E_{2}^{0}=E_{1}^{0}$ and all other data are as in Fig. 2.

Fig. 5 shows that the difference between the potentials of two anodic peaks depends on the dimensionless rate constant of the reaction (1). If $\kappa=0.003$ this difference is $225 \mathrm{mV}$ and if $\kappa=0.3$ the difference is $55 \mathrm{mV}$. The medians of these peaks are $-0.0175 \mathrm{~V}$ and $0.0175 \mathrm{~V} v s . E_{1}^{0}$, respectively. Comparing to Figs. 2 and 4 , one can observe that the second peak current increases proportionally to the increasing of the potential of minimum. In the absence of oxide the peak 
potential of reaction (13) is $0.090 \mathrm{~V} v s . E_{1}^{0}$. If the potential of minimum is close to this value, as in the case of curve 2 in Fig. 5, the reactivation of electrode surface starts at potentials at which the reaction (13) is fast and the second anodic peak current is high. One must be reminded that in Figs. 2, 4 and 5 the dimensionless rate constant of the reaction (13) is ten times bigger on reactivated surface than on the initial surface.

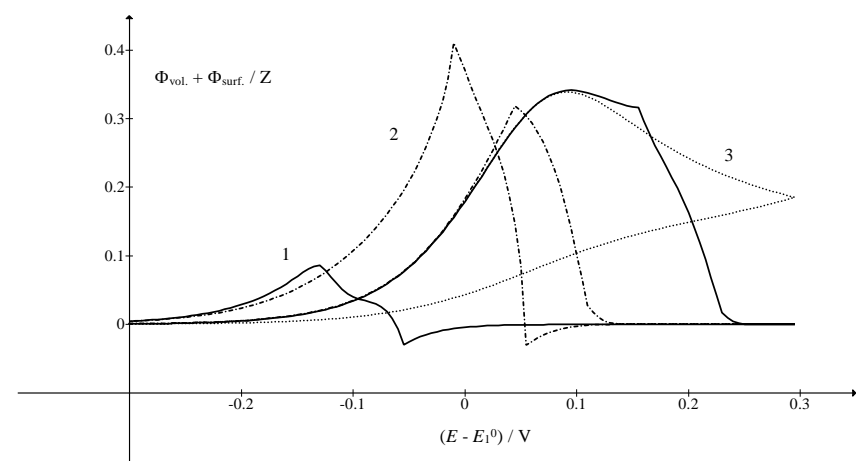

Fig. 5 The sum of dimensionless currents of volume and surface reactions (1, 2 ) and the current of volume reaction in the absence of oxide (3); $\kappa=0.003$ (1) and 0.3 (2) and all other data are as in Fig. 2.

\section{CONCLUSIONS}

Cyclic voltammogram of irreversible electro-oxidation that is inhibited by the layer of oxide on electrode surface consists of two anodic peaks and one cathodic peak. The later may be too small to be noticed if the bulk concentration of dissolved reactant is higher than $0.1 \mathrm{~mol} / \mathrm{L}$. The second anodic peak appears in the reverse branch of the response. If the second peak current is higher than the current of the forward branch at the second peak potential, then the rate constant of electro-oxidation is lower before the inactivation of electrode surface than after its reactivation. The difference between the first and the second anodic peak potentials depends on the rate constant of oxidation of electrode surface. The median of these two peak potentials depends on the difference between standard potentials of the electrode reactions (1) and (13) and on the rate constant of oxide formation.

\section{REFERENCES}

1. M. Metikoš-Huković, R. Babić, Y. Piljac, J. New Mater. Electrochem. Systems, 7, 179 (2004).

2. A. S. A. Khan, R. Ahmed, M. L. Mirza, Port. Electrochim. Acta, 27, 429 (2009).

3. A. B. Kasshyout, A. B. A. A. Nassr, L. Giorgi, T. Maiyalagan, N. A, B. Youssef, Int. J. Electrochem. Sci., 6, 379 (2011).

4. D. Zhang, L. Zhang, W. Zhang, M. Huo, J. Yin, G. Dang, Z. Ren, Q. Zhang, J. Xie, S. S. Mao, J. Materiomics, 3, 135 (2017).

5. S. Haghnegahdar, M. Noroozifar, Electroanalysis, 29, 2896 (2017).

6. W. Ye, Y. Chen, Y. Zhou, J. Fu, W. Wu, D. Gao, F. Zhou, C. Wang, D. Xue, Electrochim. Acta, 142, 18 (2014).

7. M. M. Momeni, Port. Electrochim. Acta, 33, 331 (2015).

8. T. Sheng, X. Lin, Z. Y. Chen, P. Hu, S. G. Sun, Y. Q. Chu, C. A. Ma, W. F. Lin, Phys. Chem. Chem. Phys., 17, 25235 (2015).

9. L. C. Ordoñez, P. Roquero, J. Ramirez, P. J. Sebastian, Int. J. Electrochem. Sci., 11, 5364 (2016).

10. R. Liang, A. Hu, J. Persic, Y. N. Zhou, Nano-Micro Lett., 5, 202 (2013).

11. X. Zhong, J. Chen, L. Yang, X. Sun, Indian J. Chem., 47 A, 504 (2008).

12. R. Carrera Cerritos, M. Guerra-Balcazar, R. Fuentes Ramirez, J. Ledesma Garcia, L. Gerardo Arriaga, Materials, 5, 1686 (2012).

13. D. A. Cantane, W. F. Ambrosio, M. Chatenet, F. H. B. Lima, J. Electroanal. Chem., 681, 56 (2012).

14. J. Perez, V. A. Paganin, E. Antolini, J. Electroanal. Chem., 654, 108 (2011).

15. A. F. B. Barbosa, V. L. Oliveira, J. van Drunen, G. Tremiliosi - Filho, J. Electroanal. Chem., 746, 31 (2015).

16. C. A. Martins, P. S. Fernandez, H. E. Troiani, M. E. Martins, G. A. Camara, J. Electroanal. Chem., 717 - 718, 231 (2014).

17. M. Etesami, N. Mohamed, Int. J. Electrochem. Sci., 6, 4676 (2011).

18. Z. Al Amri, M. P. Mercer, N. Vasiljević, Electrochim. Acta, 210, 520 (2016).

19.L. K. Bieniasz, Modelling electroanalytical experiments by the integral equation method, Springer, Berlin, 2015.

20.D. Britz, J. Strutwolf, Digital simulation in electrochemistry, Springer, Berlin, 2016.

21. M. Lovrić, Š. Komorsky-Lovrić, Electrochem. Commun., 86, 48 (2018). 